\title{
BAHAN MATA KULIAH \\ MATA KULIAH PSYCHOLINGUISTICS
}

\author{
${ }^{1}$ ANDI AGUSTANG \\ ${ }^{2}$ ANDI ASRIFAN \\ ${ }^{1}$ Universitas Negeri Makassar \\ ${ }^{2}$ Universitas Muhammadiyah Sidenreng Rappang
}

\section{Introductory}

Psychology is the field in which the psychological processes are studied and explained that enable people to master and use the term. Psycholinguists perform language study and how people of all ages perceive and improve language. Language research. The field is focused on linguistic findings, which are the discipline that explains the structure of the language, for language descriptions. While language learning, comprehension and production has been at the heart of psycholinguistic science, since its inception, the topic has developed substantially: psycholinguists are concerned with the neurology of language functioning, especially those studying sexual differences, aphasia, language after a congenital or acquired brain injury and developmental disorders (dysphasia). In addition to research in non-human language learning (e.g. gorilas and chimpanzees), some psycholingualists expanded their interests to discover if language as well as we know it is an exceptions.

Setelah membaca, dan menyimak penjelasan dosen, akan penyajian di bawah ini, mahasiswa diharapkan mampu memahami hal tersebut secara TERSURAT - TERSIRAT - TERSOROT:

1. $\quad .$.

a. Jelaskan yang dimaksud dengan kajian bahasa secara internal dan secara eksternal!

b. Mengapa diperlukan adanya kajian ilmu antardisiplin? Jelaskan! Jawab:

a. Kajian bahasa secara itnernal adalah kajian yang dilakukan terhadap struktur internal bahasa itu, mulai dari struktur fonologi, morfologi, sintaksis, sampai struktur wacana. Kajian secara eksternal adalah kajian yang berkaitan dengan hubungan bahasa itu dengan faktor-faktor atau hal-hal yang ada di luar bahasa, seperti faktor sosial, psikologi, etnis, seni, dan sebagainya.

b. Kajian ilmu antardisiplin diperlukan untuk mengatasi berbagai persoalan dalam kehidupan manusia yang semakin kompleks.

2. 
a. Mengapa istilah ilmu jiwa tidak dapat dipertahankan penggunaannya, sehingga harus diganti dengan istilah psikologi!

b. Konsep dasar tentang psikologi yang mentalistik, yang behavioristik, dan yang kognitifistik!

\section{Jawab:}

a. Istilah ilmu jiwa tidak dapat dipertahankan penggunaannya karena bidang ilmu ini memang tidak meneliti jiwa atau roh atau sukma, sehingga istilah itu kurang tepat.

b. Psikologi yang mentalistik mencoba mengkaji proses-proses akal manusia dengan cara mengintrospeksi atau mengkaji diri. Psikologi yang behavioristik mencoba mengkaji perilaku manusia yang berupa reaksi apabila suatu rangsangan terjadi, dan selanjutnya bagaimana mengawasi dan mengontrol perilaku tersebut. Psikologi yang kognitifistik mencoba mengkaji proses-proses kognitif manusia secara ilmiah.

3. ...

a. Jelaskan tujuan utama seorang linguis mempelajari bahasa!

b. Pembidangan linguistik berdasarkan beberapa kriteria pembidangan!

c. Bagaimana hubungan linguistik dengan psikolinguistik?

\section{Jawab:}

a. Seorang linguis mempelajari bahasa dengan tujuan utama untuk mengetahui secara mendalam mengenai kaidah-kaidah struktur bahasa, beserta dengan berbagai aspek dan segi yang menyangkut bahasa itu.

b. Secara umum pembidangan linguistik itu terbagi tiga, yaitu:

(1) Menurut objek kajiannya, yaitu linguistik mikro (struktur internal bahasa sebagai objek kajian) dan linguistik makro (kajian bahasa dalam hubungannya dengan faktor di luar bahasa).

(2) Menurut tujuan kajiannya, yaitu linguistik teoretis (ditujukan untuk mencari atau menemukan teori-teori linguistik dan membuat kaidah-kaidah linguistik secara deskriptif) dan linguistik terapan (ditujukan untuk menerapkan kaidah-kaidah linguistik dalam kegiatan praktis).

(3) Linguistik sejarah (mengkaji perkembangan dan perubahan suatu bahasa dan sejumlah bahasa) dan sejarah linguistik (mengkaji perkembangan ilmu linguistik baik mengenai tokoh-tokohnya, aliran-aliran teorinya, maupun hasil kerjanya).

c. Linguistik dan psikologi sama-sama meneliti bahasa sebagai objek formalnya.

4. ...

a. Bahasa dapat menjadi objek kajian linguistik dan dapat juga menjadi objek kajian psikologi. Coba jelaskan di mana letak perbedaannya!

b. Mengapa dirasakan perlu adanya kajian bersama antara psikologi dan linguistik? Jelaskan!

c. Coba diskusikan dengan teman Anda apa yang menjadi tujuan utama dari kajian psikolinguistik!

d. Bantuan ilmu antardisiplin apalagi yang diperlukan untuk dapat menerangkan hakikat bahasa itu? 


\section{Jawab:}

a. Dalam linguistik objek kaliannya adalah struktur bahasa, sedangkan dalam psikologi yang dikaji adalah perilaku berbahasa atau proses berbahasa.

b. Kajian bersama antara psikologi dan linguistik dirasakan perlu untuk mengkaji bahasa dan hakikat bahasa. Hal ini dikarenakan meskipun cara dan tujuannya berbeda, tetapi banyak jgua bagian-bagian objeknya yang dikaji dengan cara yang sama dan dengan tujuan yang sama, tetapi dengan teori yang berlainan. Hasil kajian kedua disiplin ini pun banyak yang sama, meskipun tidak sedikit yang berlainan.

c. Tujuan utama dari kajian psikolinguistik secara teoretis adalah mencari satu bahasa yang secara linguistik bisa diterima dan secara psikologi dapat menerangkan hakikat bahasa dan pemerolehannya.

d. Bantuan ilmu antardisiplin yang diperlukan untuk dapat menerangkan hakikat bahasa, antara lain neurofisiologi, neuropsikologis, neurolinguistik, dan sebagainya.

5. ...

a. Sebutkan dan jelaskan secara singkat mengenai subdisiplin dalam psikolinguistik!

b. Subdisiplin psikolinguistik mana yang sangat diperlukan bantuannya dalam pengajaran bahasa? Jelaskan

\section{Jawab:}

a. (1) Psikolinguistik teoretis: membahas teori-teori bahasa yang berkaitan dengan proses-proses mental manusia dalam berbahasa. (2) Psikolinguistik perkembangan: berkaitan dengan proses pemerolehan bahasa, baik pemerolehan bahasa pertama maupun bahasa kedua. (3) Psikolinguistik sosial: berkenaan dengan aspek-aspek sosial bahasa. (4) Psikolinguistik pendidikan: mengkaji aspek-aspek pendidikan secara umum alam pendidikan formal di sekolah. (5) Psikolinguistik-Neurologi (Neuropsikolinguistik): mengkaji hubungan antara bahasa, berbahasa, dan otak manusia. (6) Psikolinguistik Eksperimen: meliputi dan melakukan eksperimen dalam semua kegiatan bahasa dan berbahasa pada satu pihak dan perilaku berbahasa dan akibat berbahasa pada pihak lain. (7) Psikolinguistik terapan: berkaitan dengan penerapan dari temuan-temuan enam subdisiplin psikolinguistik di atas ke dalam bidang-bidang tertentu yang memerlukannya.

b. Subdisiplin psikolinguistik yang sangat diperlukan bantuannya dalam pengajaran bahasa adalah psikolinguistik pendidikan karena mengkaji aspek-aspek pendidikan secara umum dalam mengajar terutama pada pendidikan formal di sekolah.

6. ...

a. Psikolinguistik "katanya" terbentuk dari psikologi dan linguistik.

b. Bagaimana tanggapan Anda mengenai masalah tersebut?

Jawab:

a. Beberapa pakar berpendapat, psikolinguistik berinduk pada psikologi karena istilah itu merupakan nama baru dari psikologi bahasa (psyschology of language) yang telah dikenal beberapa waktu sebelumnya.

b. Psikolinguistik memang berinduk pada psikologi karena psikologi seseorang akan mempengaruhinya dalam berbahasa.

7. ...

a. Masalah-masalah yang menjadi pokok bahasan psikolinguistik! 
b. Pokok bahasan mana yang sangat berkatian dengan pembelajaran bahasa? Jelaskan! Jawab:

a. Masalah-masalah yang mejadi pokok bahasan linguistik, antara lain: (1) Apakah sebenarnya bahasa itu? Apakah yang dimiliki oleh seseorang sehingga dia mampu berbahasa? Bahasa itu terdiri dari komponen-komponen apa saja? (2) Bagaimana bahasa itu lahir dan mengapa dia harus lahir? Di manakah bahasa itu berada atau disimpan? (3) Bagaimana bahasa pertama (bahasa ibu) diperoleh seorang kanakkanak? Bagaimana perkembangan penguasaan bahasa itu? Di manakah bahasa kedua itu dipelajari? Bagaimanakah seseprang menguasai dua, tiga, atau banyak bahasa? (4) Bagaimana proses penyusunan kalimat atau kalimat-kalimat? Proses apakah yang terjadi di dalam otak waktu berbahasa? (5) Bagaimanakah bahasa itu tumbuh dan mati? Bagaimana proses terjadinya sebuah dialek? Bagaimana proses berubahnya suatu dialek menjadi bahasa baru? (6) Bagaimanakah hubungan bahasa dengan pemikiran? Bagaimana pengaruh kedwibahasaan atau kemultibahasaan dengan pemikiran kecerdasan seseorang? (7) Mengapa seseorang menderita penyakit atau mendapatkan gangguan berbicara (seperti afasia), dan bagaimana cara menyembuhkannya? (8) Bagaimana bahasa itu harus diajarkan supaya hasilnya baik? dan sebagainya.

b. Pokok bahasan yang sangat berkaitan dengan pembelajaran bahasa adalah mengenai bagaimana bahasa itu harus diajarkan supaya hasilnya baik. Hal ini dikarenakan pembelajaran bahasa dapat dicapai dengan baik jika cara mengajarkannya juga baik, sehingga penting untuk mengetahui cara mengajarkan suatu bahasa.

8. ...

a. Apakah bahasa memengaruhi perilaku manusia ?

b. Berikan contoh:

- Bahasa dan realita!

- Bahasa dan perilaku!

Jawab:

a. Bahasa dapat memengaruhi perilaku manusia. Karena, fungsi utama bahasa dalam kehidupan sehari-hari adalah sebagai alat komunikasi. Ketika seseorang berada dalam suatu kelompok masyarakat atau daerah maka seiring dengan kebiasaan seseorang tersebut akan terpengaruh untuk ikut menggunakan bahasa yang digunakan kelompok/daerah tersebut. Dalam kehidupan sehari-hari kegunaan bahasa sangat penting dalam menunjang aktivitas kehidupan bermasyarakat, tanpa bahasa mungkin dunia ini tidak akan seperti sekarang ini dan karena manusia tidak bisa melakukan apa-apa tanpa bahasa.Oleh karena itu sangat sebaiknya kita mengunakan bahasa yang baik dan benar untuk menunjukkan sisi positif dari diri kita kepada orang lain. Hal ini tentu saja menguntungkan kedua belah pihak agar kita dapat dihormati dan orang lain pun akan merasa sangat senang karena dihargai.

b.

- Bahasa dan realita:

Contohnya: jika seseorang yang sedang berjalan di pinggir jalan lalu mendengarkan suara klakson kendaraan dari belakang, maka walau tanpa melihat kebelakang orang tersebut akan mengetahui bahwa klakson yang dibunyikan oleh 
kendaraan di belakang adalah sebuah isyarat agar orang yang sedang berjalan untuk berjalan lebih ke jalur kiri lagi demi keselamatan pejalan kaki tersebut.

\section{- Bahasa dan perilaku:}

Contohnya: ketika seorang anak berbicara kepada orang tua/orang yang lebih tua, maka anak tersebut tidak boleh menggunakan intonasi yang lebih tinggi dari orang yang lebih dewasa/lebih tua.

9. ...

"Manusia memiliki bahasa, bagaimana dengan binatang? Mengapa binatang tidak dapat berbahasa layaknya manusia? Jelaskan pendapat Anda dengan disertai bukti."

\section{Pembahasan:}

Kita lihat semut saling menyentuhkan sungut dan kakinya bila bertemu dengan semut lain. Induk ayam akan mengeluarkan bunyi-bunyi tertentu untuk memanggil anak-anaknya ketika menemukan makanan. Kucing juga akan menciptakan bunyi-bunyian yang khas (bahkan terkadang mirip tangisan bayi) ketika ia hendak menarik perhatian lawan jenis. Demikian pula halnya dengan lebah. Lebah juga memiliki tarian-tarian tertentu untuk memberitahu teman-temannya ketika menemukan nektar. Mereka akan membuat tarian yang menunjukkan dimana tempat nektar tersebut berada, berapa banyak, berapa jauh jaraknya, apakah ada ancaman atau tidak untuk sampai ke sana, dan sebagainya.

Dari fakta ini tampak bahwa binatang juga memiliki "bahasa", sekalipun bahasa yang digunakan oleh binatang berbeda dengan bahasa yang dimiliki oleh manusia. Binatang juga menggunakan bahasa untuk berkomunikasi dengan spesies yang sejenis, seperti halnya manusia berbahasa untuk berkomunikasi dengan manusia lainnya. Namun, bentuk komunikasi yang dilakukan oleh binatang juga terbatas. Bagi binatang, bahasa hanya berfungsi untuk memenuhi kebutuhan-kebutuhan primitif (primer) mengenai keadaan emosi, tanda adanya bahaya, mengenali sesama golongan, memanggil pasangan atau anak, adanya makanan di tempat tertentu, dan percumbuan (Markam, 1991: 21). Apabila manusia memakai sebagian besar otaknya untuk proses mental, termasuk proses kebahasaan, binatang lebih banyak memakai otaknya untuk kebutuhan-kebutuhan fisik (Dardjowidjojo, 2010: 208).

Mengapa manusia dapat berbahasa sedangkan binatang tidak ? Studi dalam neurolinguistik menunjukkan bahwa manusia ditakdirkan memiliki otak yang berbeda dengan primata lainnya, baik dalam struktur maupun fungsi. Pada manusia ada bagianbagian otak yang dikhususkan untuk kebahasaan, sedangkan pada binatang bagian-bagian ini tidak ada. Pada makhluk lain seperti simpanse dan gorilla juga tidak terdapat daerahdaerah yang dipakai untuk memproses bahasa (Dardjowidjojo, 2010: 208). Dari segi biologi, manusia juga ditakdirkan memiliki struktur biologi yang berbeda dengan binatang. Mulut manusia misalnya, memiliki struktur yang memungkinkan manusia untuk mengeluarkan bunyi yang berbeda-beda. Ukuran ruang mulut dalam bandingannya dengan lidah, kelenturan lidah, dan tipisnya bibir membuat manusia mampu untuk menggerak-gerakkannya secara mudah untuk menghasilkan bunyi-bunyi yang distingtif (Dardjowidjojo, 2010: 4).

Orang telah banyak melakukan penelitian dan mencoba mengajar binatang untuk berbahasa, tetapi tidak satu pun dari mereka yang berhasil. Gua, seekor simpanse yang 
diteliti oleh Prof. Kellog dan istrinya, dapat memahami sekitar tujuh puluh kata tetapi ia tidak dapat berbicara. Vicki, simpanse yang diajar oleh Dr. Hayes dan istrinya, hanya dapat mengatakan papa, mama, cup, dan up. Prof. Gardner dan istrinya juga melatih simpanse Washoe bahasa isyarat. Dia berhasil menguasai sekitar 100 kata dala waktu 21 bulan, tetapi tetap saja tidak dapat berbicara. Dan terakhir, simpanse yang dilatih oleh Herbert Terrace yang dinamakan Nim Chimsky tampaknya menunjukkan adanya kemampuan menggabung kata, tetapi setelah diteliti lebih lanjut kedapatan bahwa kemampuan itu semu belaka (Dardjowidjojo, 2010: 5).

Simpanse merupakan primata yang paling dekat dengan manusia. Bahkan, menurut penelitian terbaru, DNA kedua makhluk ini mirip sampai 95-99\% (Dardjowidjojo, 2000: 52). Namun, tetap saja primata seperti simpanse tidak dapat menguasai bahasa meskipun sudah dididik dan dilatih secara khusus. Semua usaha yang berujung pada ketidakberhasilan melatih hewan berbahasa menggunakan bahasa manusia tersebut menunjukkan bahwa bahasa manusia merupakan sesuatu yang bersifat insani.

Hal itu senada dengan teori pemerolehan bahasa yang diajukan oleh Noam Chomsky, bahwa pemerolehan bahasa bersifat kodrati dari dalam diri manusia. Manusia dapat berbahasa karena ia memang telah terlahir dengan seperangkat piranti yang memungkinkan dia untuk berbahasa, kapasitas otak yang sesuai, dan faktor biologis yang mendukung. It conveys the idea that people know how to talk in more or less the sense that spiders know how to spin webs...spiders spin spider webs because they have spider brains, which give them the urge to spin and the competence to succeed (Pinker, 1994: 18).

\section{Bacaan Inspirasi}

Ma'na, P., Agustang, A., Salusu, J., Ikhsan, A., \& Dirawan, G. D. (2015). Decision making strategic value based local wisdom Tongkonan North Toraja. Man India, 95(3), 633-639.

Upe, A., Salman, D., \& Agustang, A. (2019). The effects of the exploitation of natural resources towards risk society construction in Southeast Sulawesi Province, Indonesia. Journal of Degraded and Mining Lands Management, 6(2), 1587.

Awaru, A. O. T., Idris, R., \& Agustang, A. (2018, October). Sexual Education at High School Sinjai East. In 1st International Conference on Social Sciences (ICSS 2018). Atlantis Press.

Idris, M., Ramli, M., Agustang, A., \& Kesuma, A. I. (2015). Bureaucracy Ethics Based in Public Service Local Wisdom in Gowa. Mediterranean Journal of Social Sciences, 6(6 S4), 419-419.

Agustang, A., Pada, A. T., \& Bastiana, M. (2018, October). Social Interaction of Local Communities With Migrants and Changes in The Structure of Local Communities (Study on Plural Society in Makassar Industrial Area). In 1st International Conference on Social Sciences (ICSS 2018). Atlantis Press.

Wardah, S., Salman, D., Agustang, A., \& Fahmid, I. M. (2017). The Contestation of Organic and NonOrganic Agricultural Knowledge in Sustainable Agriculture. Mediterranean Journal of Social Sciences, 8(2), 245-245.

Agustang, A. (2018). SIMBOLIKHAJI: Studi Deskriptif Analitik pada Orang Bugis. Al-Qalam, 15(2), $317-$ 334.

Pannyiwi, R., Agustang, A., Kasnawi, T., Pada, A. T., Yani, A., \& Syam, S. (2020). Social Network for Drug Circulation in Sidenreng Rappang Regency, Indonesia. Systematic Reviews in Pharmacy, 11(9), 575-577.

Agustang, A., \& Soelthan, A. (2015). Analysis of the Inhibiting Factors of Transparency in the Implementation of Local Governance. Mediterranean Journal of Social Sciences, 6(6 S4), 464.

Nain, U., \& Agustang, A. (2020). Analysis On The Utilization Of Village Funds In Cash For Work Program In Bulukumba Regency, South Sulawesi Indonesia. International Journal of Advanced Science and Technology, 29(7s), 2811-2818. 
Azis, F., Idris, R., \& Agustang, A. (2017). Involution Fisheries: Post-Study Model of National Program in Integrated Movement at Community Fishermen's Village Development Arungkeke, Jeneponto. Mediterranean Journal of Social Sciences, 8(1), 441.

Agustang, A. D. M. P., \& Nur, H. (2020). Konflik Mahasiswa Parang Tambung Universitas Negeri Makassar. Phinisi Integration Review, 3(1), 46-54.

Rasyid, R., Agustang, A., Maru, R., Agustang, A. T. P., \& Sudjud, S. (2020). PENYULUHAN PENCEGAHAN PENYALAHGUNAAN NARKOBA DI KALANGAN PELAJAR SMP NEGERI 6 DUAMPANUA KABUPATEN PINRANG. JMM (Jurnal Masyarakat Mandiri), 4(2), 116-123.

Rahmania, S., \& Agustang, A. (2017). PRESEPSI MAHASISWA FIK TERHADAP PENYIMPANGAN SEKSUAL LESBIAN (STUDI KASUS PADA MAHASISWA FIK UNM). JURNAL SOSIALISASI, 162-168.

Ashar, A., \& Agustang, A. (2020). Dampak Sosial Dana Desa Dalam Kesejahteraan Masyarakat Di Desa Kalola, Kecamatan Maniangpajo, Kabupaten Wajo. Jurnal Sosialisasi: Jurnal Hasil Pemikiran, Penelitian dan Pengembangan Keilmuan Sosiologi Pendidikan, (1), 19-25.

Yusuf, M., \& Agustang, A. (2020). DINAMIKA PERUBAHAN SOSIAL EKONOMI PADA MASYARAKAT KINDANG KABUPATEN BULUKUMBA. Jurnal Sosialisasi: Jurnal Hasil Pemikiran, Penelitian dan Pengembangan Keilmuan Sosiologi Pendidikan, (2), 31-37.

Fransina, M., \& Andi, A. (2019). THE ANALYSIS OF EXISTENCE OF MIGRATION IN THE CONTEXT OF BASUDARA COMMUNITY IN AMBON CITY, INDONESIA. Russian Journal of Agricultural and Socio-Economic Sciences, 94(10).

Usman, A., Agustang, A., Djalal, D., \& Annas, S. (2018, October). The Contribution Of Supporter Community In Maximizing Their Role For The Advancement Of Makassar Football Club (PSM). In 1st International Conference on Social Sciences (ICSS 2018). Atlantis Press.

Agustang, A., \& Oruh, S. Factors affecting of heropnam of mental disorders in Dadi Regional Hospital in South Sulawesi Province. Man In India, 97(11), 233-244.

Pratiwi, E. L., \& Agustang, A. (2018). PERSEPSI ORANGTUA SISWA TERHADAP TINDAKAN GURU DALAM MENDISIPLINKAN SISWA DI SMK YPKK LIMBUNG. JURNAL SOSIALISASI, 6-10.

Asri, A., Kasnawi, T., \& Agustang, A. Actors' Social Tensions on Traditional Birth Attendants and Midwife Partnerships in Childbirth Assistance (Sociology of Health Study in Bulukumba Regency).

Bahri, S., Kasnawi, T., Agustang, A., \& Adam, A. (2017). Vegetarian Community Social Movement (Analysis of Health Sociology in Makassar). The Social Sciences, 12(10), 1824-1831.

Djalante, A., Agustang, A., Tahmir, S., \& Sahabuddin, J. A Disadvantaged Tribe in Bajoe Village, Bone Regency: A Phenomenological Research on Bajo Tribe's Social Life in Bone Regency, South Sulawesi.

Rahmawati, R., \& Agustang, A. (2018). PERBANDINGAN POLA ASUH ORANG TUA SISWA BERPRESTASI DENGAN SISWA YANG TIDAK BERPRESTASI DI SMA NEGERI 2 GOWA. JURNAL SOSIALISASI, 115-119.

Agustang, A. (2018). PERAN WALI KELAS DALAM PENYELESAIAN KONFLIK ANTAR SISWA DI SMA NEGERI 1 PINRANG. JURNAL SOSIALISASI, 12-16.

Irnawaty, I., \& Agustang, A. (2019). SMARTPHONE ADDICTION PADA MAHASISWA PENDIDIKAN SOSIOLOGI FAKULTAS ILMU SOSIAL UNIVERSITAS NEGERI MAKASSAR. JURNAL SOSIALISASI, 41-46.

Zainuddin, M., \& Agustang, A. (2019). KONTROL SOSIAL ORANGTUA TERHADAP PENGGUNAAN SMARTPHONE PADA REMAJA (STUDI DI DESA GIRING-GIRING KECAMATAN BONTONMPO KABUPATEN GOWA. JURNAL SOSIALISASI, 68-73.

Sofyan, Y., \& Agustang, A. (2018). PENERAPAN MODEL PEMBELAJARAN KOOPERATIF TIPE NHT (NUMBERED HEADS TOGETHER) TERHADAP KEAKTIFAN BELAJAR SISWA KELAS XI IPS 1 SMAN 8 MAKASSAR. JURNAL SOSIALISASI, 158-165.

Agustang, A. (2018). PENERAPAN PUNISHMENT DALAM MEMBENTUK KARAKTER DISIPLIN SISWA DI SMA NEGERI 1 TAKALAR. JURNAL SOSIALISASI, 126-130.

Amiruddin, T. K., Agustang, A., \& Idris, R. (2014). RELIGIOUS CONVERSION IN MARRIED LIFE IN MAKASSAR, THE CASE OF CHRISTIANITY TO ISLAM. JOURNAL OF ACADEMIC RESEARCH, 6(6), 264.

Machmuddin, H., Agustang, A., Kahar, F., \& Bustan, N. (2015). IMPROVING THE QUALITY OF PRIMARY HEALTH SERVICES IN THE PERSPECTIVE OF PARTICIPATORY GOVERNANCE. International Journal of Academic Research, 7(1).

Agustang, A., \& Sahabuddin, J. (2020, October). MODEL KOLABORASI SOSIAL PENDIDIKAN KARAKTER DI SEKOLAH SWASTA KECAMATAN BISSAPPU KABUPATEN BANTAENG. In PROSIDING SEMINAR DAN DISKUSI PENDIDIKAN DASAR. 
Astinah, A., Idris, R., \& Agustang, A. (2020). AGILE LEADERSHIP AND DIVORCE EDUCATION: STUDY ON WOMEN'S PERCEPTION. Humanities, 8(3), 323-330.

Muis, I., Agustang, A., \& Adam, A. (2020). Elderly Poverty: Social Demographic, Work Distribution, Problem Health \& Social Protection. Asian Journal of Social Sciences \& Humanities Vol, 9(1).

Agustang, A. (2020). Symbolic Violence towards Students in the Context of the Existence of the Stereotypical Frames of Lecturers and Students in the Higher Education System in Indonesia. PalArch's Journal of Archaeology of Egypt/Egyptology, 17(2), 249-258.

Asrifan, A. (2009). Using songs in teaching English language for the young learners. ParePare: unpublished.

Puasa, K., Asrifan, A., \& Chen, Y. (2017). Classroom Talk in Bilingual Class Interaction. Research in Pedagogy, 7(1), 106-121.

Nadirah, N., Tahir, M. H., \& Asrifan, A. (2019). THE ABILITY TO TRANSLATE ENGLISH PHRASES INTO INDONESIAN AND THE DIFFICULTIES FACED BY THE ELEVENTH GRADE STUDENTS OF SMAN 1 PANCARIJANG. JOURNAL OF ADVANCED ENGLISH STUDIES, 2(1), 41-46.

Apdy, A. P. R., \& Asrifan, A. (2019, April). The Chinese mime game in teaching vocabulary on EFL classroom. In PROCEEDINGS OF THE 65th TEFLIN INTERNATIONAL CONFERENCE (Vol. 65, No. 01).

Taslim, T., Asrifan, A., Chen, Y., \& Nurdania, N. R. (2019). CORRELATION BETWEEN STUDENT'S VOCABULARY MASTERY AND SPEAKING SKILL. JOURNAL OF ADVANCED ENGLISH STUDIES, 2(2), 65-76.

Muthmainnah, M., Asrifan, A., Al Yakin, A., \& Sahabuddin, C. (2019, April). The use of dictogloss technique on ELT classroom: An experiment study of students listening comprehension. In PROCEEDINGS OF THE 65th TEFLIN INTERNATIONAL CONFERENCE (Vol. 65, No. 01).

Mutmainnah, M., Azis, S., Maulidya, U., \& Asrifan, A. (2017). Glory Style in Mandar Song Lyrics: A study of Mandar Tribe in South Sulawesi, Indonesia. JOURNAL OF ADVANCES IN LINGUISTICS, 8(1), 1286-1291.

Asrifan, A., Rinantanti, Y., Tang, S., \& Nadirah, N. (2019). THE 3-DIMENSION PICTURES IN INCREASING THE STUDENTS ABILITY AND INTEREST TO WRITE DESCRIPTIVE COMPOSITION. JOURNAL OF ADVANCED ENGLISH STUDIES, 2(1), 19-30.

Asrifan, A., Nadira, N., \& Haedar, H. (2018). IMPROVING STUDENTS'READING COMPREHENSION OF DESCRIPTIVE TEXT THROUGH COLLABORATIVE MURDER. JOURNAL OF ADVANCED ENGLISH STUDIES, 1(2), 21-31.

Asrifan, A. (2015). Analysis of English Students' Learning Style in Bilingual Class. International Journal of Literature and Arts, 3(4), 34.

Farahdiba, S., \& Asrifan, A. (2016). Speaking Ability and Psychological Barriers of the Second Year Students of Hotel Department of SMKN 1 Sidenreng Kabupaten Sidrap in Speaking English. Asian EFL Journal, (89), 41.

Asrifan, A. (2012). Increasing the Students Ability to Write Descriptive Composition at SMP Negeri 13 Parepare by using the 3-Dimension Pictures.

Tang, S., Asrifan, A., Chen, Y., Haedar, H., \& Agussalim, M. (2019). THE HUMOR STORY IN TEACHING READING COMPREHENSION. JOURNAL OF ADVANCED ENGLISH STUDIES, 2(2), 77-87.

Nurwanti, N., Asrifan, A., \& Haedar, H. (2019). THE APPLICATION OF COOPERATIVE LEARNING: JIGSAW II TECHNIQUE IN IMPROVING STUDENTS'READING COMPREHENSION OF EXPOSITORY TEXT. JOURNAL OF ADVANCED ENGLISH STUDIES, 2(1), 31-40.

Asrifan, A. (2016). The Effectiveness of Think-Pair-Share Technique in Improving Studentsâ€ ${ }^{\mathrm{TM}}$ Speaking Ability and Interest. English Literature and Language Review, 2(3), 24-35.

Asrifan, A., Muthmainnah, M., Al-Yakin, A., Sahabuddin, C., \& Haedar, H. (2018). THE CAUSEEFFECT TECHNIQUE IN TEACHING RECOUNT WRITING. JOURNAL OF ADVANCED ENGLISH STUDIES, 1(2), 63-72.

Asrifan, A., Vargheese, K. J., Syamsu, T., \& Amir, M. (2020). ESP COURSE DESIGN: THE NEED ANALYSIS ON TOURISM DEPARTMENT IN INDONESIA VOCATIONAL HIGH SCHOOLS. JOURNAL OF ADVANCED ENGLISH STUDIES, 3(2), 69-77.

Asrifan, A., Ghofur, A., \& Azizah, N. (2020). Cheating Behavior in EFL Classroom (A Case Study at Elementary School in Sidenreng Rappang Regency). OKARA: Jurnal Bahasa dan Sastra, 14(2), 279-297.

Nadirah, N., Asrifan, A., Vargheese, K. J., \& Haedar, H. (2020). INTERACTIVE MULTIMEDIA IN EFL CLASSROOM: A STUDY OF TEACHING READING COMPREHENSION AT JUNIOR HIGH SCHOOL IN INDONESIA. JOURNAL OF ADVANCED ENGLISH STUDIES, 3(2), 131-145. 
Muthmainnah, A. R., Atmowardoyo, H., Salija, K., \& Asrifan, A. (2020). Literary Work as Teaching Materials: A Study of Students and Lecturers Needs Analysis. Solid State Technology, 63(5), 394-407.

Tilome, A. A., Agustang, A., Jasruddin, M. S., \& Asrifan, A. (2020). Social Exchange of Political Elites in the Regional Leader Election of Gorontalo Province, Indonesia. Solid State Technology, 63(5), 521-531.

Pacinongi, A., \& Asrifan, A. (2020). Bimbingan Pengawas Berkelanjutan dalam Mewujudkan Pendidikan Karakter Bangsa dalam Kegiatan Belajar Mengajar Penjaskes. Celebes Education Review, 2(1), 1-7.

Gunawan, G., \& Asrifan, A. (2020). Penerapan Kerja Kelompok Kegiatan MGMP Guru Ekonomi dalam Menyusun RPP untuk Meningkatkan Kompetensi Pedagogik. Celebes Education Review, 2(1), 31-36.

Yusuf, I., \& Asrifan, A. PENINGKATAN AKTIVITAS KOLABORASI PEMBELAJARAN FISIKA MELALUI PENDEKATAN STEM DENGAN PURWARUPA PADA SISWA KELAS XI IPA SMAN 5 YOGYAKARTA. Editorial Team, 32.

Al Yakin, A., Sahabuddin, C., Rahayu, A., Fitrah, N., \& Arifin, M. (2020). Political Celebrification and Electability: A Study of Political Phenomena Imaging in Election Polewali Mandar District, West Sulawesi, Indonesia. Solid State Technology, 63(5), 632-646.

Junaedah, S. B. T., \& Ahmad, M. A. (2020). The Outdoor Learning Modules Based on Traditional Games in Improving Prosocial Behaviour of Early Childhood. International Education Studies, 13(10).

Octaberlina, L. R., \& Muslimin, A. I. (2020). Efl students perspective towards online learning barriers and alternatives using moodle/google classroom during covid-19 pandemic. International Journal of Higher Education, 9(6), 1-9.

Octaberlina, L. R., \& Anggarini, I. F. (2020). Teaching vocabulary through picture cards in Islamic Elementary School: a case study in Nida Suksa School, Thailand. Jurnal Madrasah, 13(1), 2638 .

Octaberlina, L. R. (2016). Plagiarism in English language theses in Indonesia. Jurnal IImu Pendidikan, 14(3).

Octaberlina, L. R., \& Anggarini, I. F. (2020). Teaching vocabulary through picture cards in Islamic Elementary School: a case study in Nida Suksa School, Thailand. Jurnal Madrasah, 13(1), 2638.

Asrifan, A., Zita, C. T., Vargheese, K. J., Syamsu, T., \& Amir, M. (2020). THE EFFECTS OF CALL (COMPUTER ASSISTED LANGUAGE LEARNING) TOWARD THE STUDENTS'ENGLISH ACHIEVEMENT AND ATTITUDE. JOURNAL OF ADVANCED ENGLISH STUDIES, 3(2), 94106.

Asrifan, A. (2021). ACADEMIC WRITING. LawArXiv. January, 2. https://doi.org/10.31228/osf.io/x2s7e

Asrifan, A. (2020). TUTORIAL PENGGUNAAN QUIZIZZ (www. quizizz. com) PADA PEMBELAJARAN. https://doi.org/10.31219/osf.io/kqnza

Asrifan, A. (2021). Abd Ghofur.". THE USE OF READING CIRCLES IN INCREASING STUDENTS SPEAKING ABILITY AT THE ELEVENTH GRADE SMK NEGERI, 1. https://doi.org/10.31219/osf.io/8vjxy

Asrifan, A. (2020). Pandemic, Humanity and Education. https://doi.org/10.31219/osf.io/q2gpk

Asrifan, A. (2021). USING CAT AND MOUSE GAME TO IMPROVE STUDENT'S SPEAKING ABILITY AT THE ELEVENTH GRADE OF MA YMPI RAPPANG. https://doi.org/10.31219/osf.io/phtvn

Asrifan, A., \& Ghofur, A. (2021). THE USE OF READING CIRCLES IN INCREASING STUDENTS SPEAKING ABILITY AT THE ELEVENTH GRADE SMK NEGERI 1 PANCARIJANG. https://doi.org/10.31219/osf.io/8vjxy

Asrifan, A. (2021). Book Review: Halliday. 1989. Spoken and Written Language. Oxford University Press. https://doi.org/10.31219/osf.io/ej8tb

Asrifan, A., \& Ghofur, A. (2021). TALK, ACTION, SILENCE, INTERRUPTION AND THEIR IMPLICATIONS IN BUGINESE SOCIETY (SOPPENG REGENCY). https://doi.org/10.31219/osf.io/pv3ku

Asrifan, A. (2020). PENILAIAN BERBASIS ANDROID MENGGUNAKAN APLIKASI PLICKERS. https://doi.org/10.31219/osf.io/htreq 